\title{
268
}

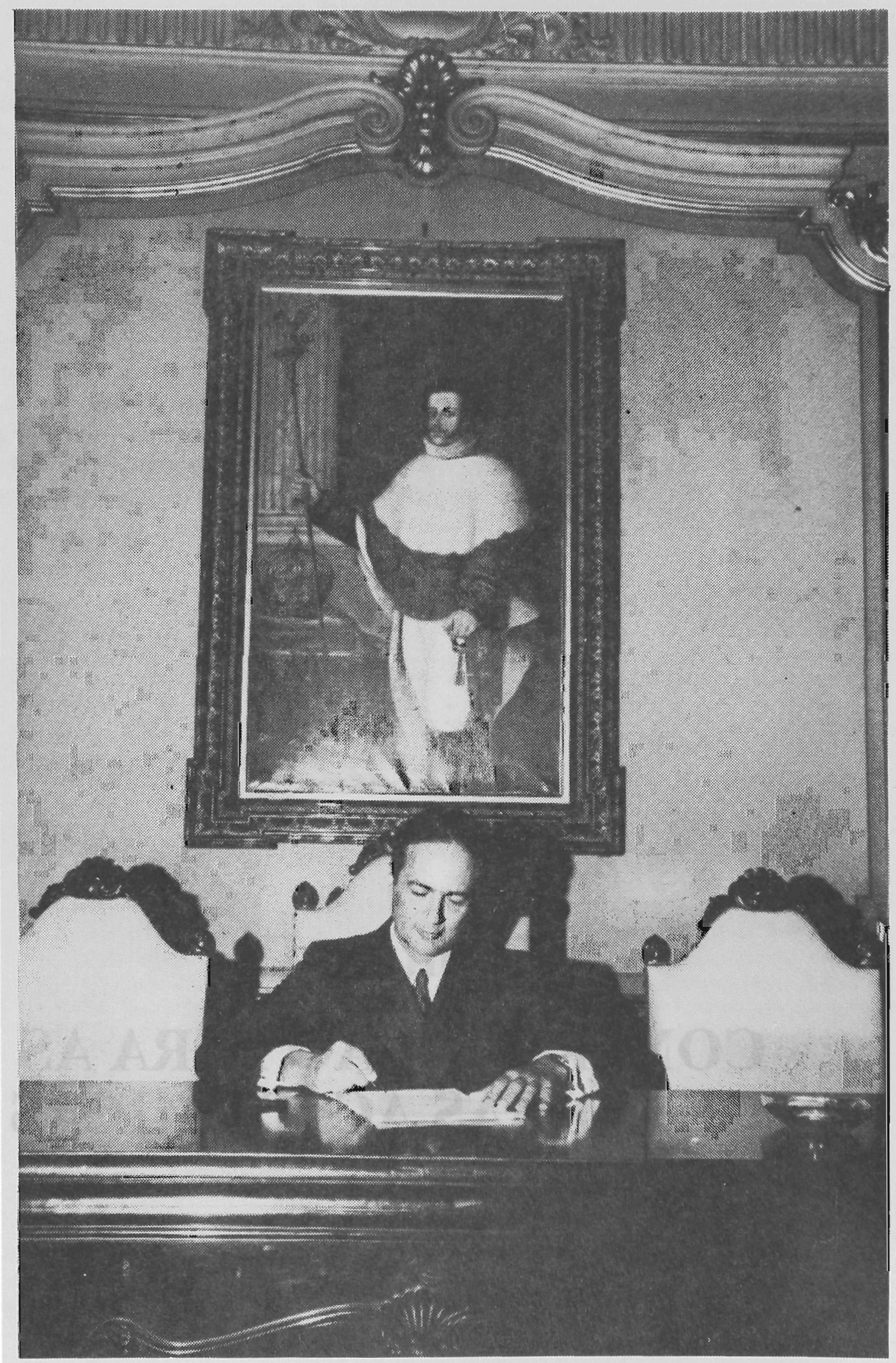




\section{Discurso de Posse do Professor Doutor Antonio Junqueira de Azevedo, Titular do Departamento de Direito Civil}

Antonio Junqueira de Azevedo

Vice-Diretor da Faculdade de Direito

Excelentíssimo Senhor Diretor da Faculdade de Direito da Universidade de São Paulo

Excelentíssimo Senhor Prof. José Carlos Moreira Alves. Presidente do S.T.F. Excelentíssimo Senhor Professor Emérito Luís Eulálio de Bueno Vidgal

Excelentíssimos Senhores Professores da Congregação,

Senhores Professores,

Senhoras e Senhores,

Meus alunos.

Compreendeis certamente a plenitude de sentimentos que invadem minha alma, ao falar no salão nobre desta Escola, há mais de um século, coração da vida cívica, política, social e jurídica de São Paulo.

Esta tradicional cerimônia de recepção do Professor Titular representa o ponto final da carreira universitária. Seria interessante se este que vos fala pudesse olhar para o passado e dizer o quanto foi grande o seu esforço para chegar até aqui. Infelizmente, porém, sinto como se ainda não tivesse chegado.

Os pequenos resultados dos meus esforços e minha solidariedade para com meus irmãos de nacionalidade impedem-me de considerar que o combate esteja terminado. Pelo contrário, encaro esta cerimônia, não como a extrema unção do professor, e sim, como o batismo para o ingresso do neófito num amplo movimento de restauração nacional.

Todos vós conheceis a parábola do semeador (Mt 13, 1-13; Mar 4, 1-20; Lc 8, 4-15). Trata-se de parábola muito grata a oradores, políticos, professores, porque diz respeito às virtudes da palavra. "Saiu o semeador a semear" e comprazem-se os intérpretes em comentar as quatro atitudes de quem ouve: a da- 
queles que praticamente não recebem a palavra proferida; a dos que a ouvem, mas são inconstantes; a dos que a ouvem, mas com o tempo deixam-se levar pelas preocupaçōes mundanas; e, finalmente, a dos que aceitam e deixam-na frutificar.

Ora, observo que, além da lição conhecida, há, nesta parábola, algo estranho do ponto de vista puramente humano: é que este semeador semeia loucamente - ou, generosamente - aos quatro ventos; uma parte das sementes cai, afinal, à beira do camimho, outra, entre pedregulhos, mais outra, entre espinhos, e somente uma parte, em terra boa. É como se o semeador dissesse "sou semeador, minha função é semear. Semeemos, pois, sem olhar para trás, sem olhar para onde".

Se o exemplo é esse, se aqui está o coração cívico, político, social e jurídico de São Paulo e se me dão voz, tentarei imitar, como puder e souber, o semeador "louco", aproveitando a imprecisão das palavras "cívico" "político" "social" e "jurídico" semeando uma idéia em cada campo, consciente de que o servo não é melhor que seu senhor.

No campo cívico, a federação brasileira como está, a quase nada corresponde. São mais de uma vintena de Estados, inteiramente díspares do ponto de vista territorial, econômico, demográfico e, principalmente, cultural.

A insatisfação é geral. A equiparação de Estados como a Bahia ao Acre, Rio de Janeiro a Rondônia constitui evidente inadequação. Esta equiparação nāo corresponde à nossa realidade geográfica e histórica.

As províncias brasileiras são somente sete e precisam encontrar expressão constitucional, a fim de não nos apagarmos todos numa padronização global, que acabará por destruir a identidade brasileira.

As sete províncias são: Bahia, cujo modo de falar, agir, comer, e, até mesmo, andar, cónstitui, na ordem cronológica, o primeiro modo de ser da cultura brasileira; Rio de Janeiro, símbolo da beleza da nação, um Estado hoje humilhado, sem um papel à altura de sua voz, confundido como está com Estados menores; Minas Gerais - quem uma vez levantou às seis da manhã e foi por estradas de terra serpenteando entre montanhas, num dia de sol, cruzou com o caminhäo do leite, com um cavalo perdido na estrada, viu uma vaca na cerca, passou por grupos de quatro ou cinco crianças, indo a pé, com as malinhas a caminho da escola, sabe: Minas, é especial! E há São Paulo: os primeiros paulistas foram severos e rudes; a imigração de italianos, sírio-libaneses, japoneses, e ainda, a vinda de elevado número de brasileiros da Bahia e do Nordeste, em nada alterou essa característica: éramos simples, somos simples, consideramos o trabalho necessário, a elegância não é nosso forte, em São Paulo o que 
queremos é que a palavra valha. Pernambuco, terra de coragem; Rio Grande do Sul, baluarte da cultura portuguesa frente ao espanhol, e Pará, contitui as outras três províncias.

Os demais Estados são meras variações das sete províncias; eles que se agrupem em torno das sete capitais: Salvador, Rio de Janeiro, Belo Horizonte, São Paulo, Recife, Porto Alegre e Belém.

A Assembléia Constituinte, a ser instalada, já encontrou condicionamentos prévios dificilmente removíveis. Um deles é justamente este: o de que, tendo a eleição sido feita para deputados e senadores, a suposição é a de que o Senado, órgão representativo da Federação, permaneça como está.

Entretanto, mesmo sem alterar esses dados e mantida também a organização jurídica e administrativa de cada Estado, nada impede que se crie, com vantagem até mesmo didática, uma nova Câmara, com funçōes legislativas e consultivas que agrupe em sete províncias todos os Estados, e reflita o Brasil real, o Brasil histórico, a unidade nacional na diversidade harmônica de suas culturas.

E passemos ao campo político.

A persistência, como está, do modelo proporcional de eleição para deputado é um absurdo que clama aos céus. Até mesmo os mais interessados e preparados dos eleitores não ficaram sabendo quantos e quais eram todos os candidatos na eleição que se encerrou. Não é de admirar que os votos em branco e nulos tenham suplantado os sufrágios dados aos mais populares candidatos (e é preciso lembrar que, entre os votos computados, estão muitos, feitos literalmente sem escolha, isto é, por pessoas que se fixaram em um nome, ou em um número, sem qualquer comparação entre candidatos).

Esta situação não pode permanecer; não fiquemos como as crianças que resmungam na praça, a reclamar da chamada "classe política". Lutemos pela introdução, parcial, do sistema distrital, isto é, da divisão do Estado em circunscrições e da escolha entre somente quatro ou cinco candidatos por circunscrição. Experimentemos também, vencendo velhos preconceitos, associar a esse sistema duplo, mais o sistema corporativo, de escolha indireta, por categorias, de forma a haver, na Câmara, representantes dos operários, dos empresários urbanos, dos agricultores, dos produtores rurais, dos professores, dos advogados, dos médicos, dos juízes, dos promotores, etc. Diante do quadro desenhado pela última eleição, é o caso de gritar: "Para deputado, indiretas já!"

Reflitamos um pouco, em terceiro lugar, sobre a questão social. Se, em princípio, são três os fatores da produção econômica, natureza, capital e traba- 
lho, organizados pelo empresário, é preciso antes de mais nada, que este reconheça o primado do trabalho, fator humano, sobre os outros dois. É indispensável também, sempre em linha de princípio, e como afirmou o Papa João Paulo II, na encíclica "Laborem Exercens", que trabalhador e empresário se vejam como colaboradores de uma obra comum.

Por outro lado, é de se observar ainda que alguns conceitos jurídicos pecam por excessiva abstração; à própria palavra "propriedade" sofre desse mal, porque encobre realidades diversas. Nela, cabem tanto bens móveis de pouco valor, quanto a casa de residência, o imóvel rural, ou as grandes unidades de produção, possuidas através das açōes da sociedade anônima.

Ora, dentro desses parâmetros, estamos vivendo uma situação paradoxal. Sobre a reforma nas grandes empresas, que têm milhares de empregados, em que o fator humano e organizacional predomina largamente e onde seria razoável que os trabalhadores tivessem participação, ainda que minoritária na administração, pouco se fala.

O fato se agrava quando se trata das empresas de comunicação, em que nem os empregados nem a sociedade, diretamente interessada, têm voz ativa, ficando tudo sob orientação, o poder, muitas vezes, de um só homem.

E é justamente na atividade rural, em que o papel dos fatores capital e natureza têm maior vulto e em que, pelo menos de Minas Gerais para o Sul, a economia funciona relativamente bem, que se fala em reforma.

O excesso populacional de nossas grandes capitais não é fenômeno brasileiro, fruto de um subdesenvolvimento rural; é fenômeno universal, fruto do desenvolvimento tecnológico. E é preciso nāo confundir o problema social do "bóia-fria" com o do trabalhador da terra, eis que o primeiro é um caso especial, ele é antes o.trabalhador da usina de cana, - empresa industrial, e não, rural.

Enfim, em matéria social, penso que os espíritos mais generosos estão errando de alvo; tratam do que não é preciso e silenciam sobre o fundamental especialmente, a indispensável reforma nos meios de comunicação.

Finalmente, no campo estritamente jurídico, há o problema da tradicional divisão do direito em público e privado. Esta divisão vem, há alguns decênios, sendo considerada ultrapassada e não são poucos os doutrinadores que procuram situar as matérias de sua especialidade em um terceiro gênero. No meu modo de entender, estas colocações se devem a uma confusão originada no século XVIII e início do século XIX, pela qual o direito privado foi indevidamente amarrado à vontade individual. Considerando as progressivas e inevitáveis li- 
mitações à autonomia do particular torna-se evidente que sua identificação com o direito privado somente pode levar ao desapreço, senão à extinção, deste ramo do direito. No entanto, o direito privado não é o direito do indivíduo, e sim o direito da sociedade, por oposição ao direito público, que é o direito do Estado. O primeiro é social e o segundo, estatal. Diferem, pois, no objeto. Diferem também na origem e nos caracteres. É preciso lembrar que, até mesmo no ápice do absolutismo monárquico, os reis raramente criavam o direito civil. Este direito brotava diretamente da sociedade. Na célebre frase atribuída a Luís XIV, "L'Etat c'est moi", "Estado" refere-se ao "aparato estatal", não às normas de direito privado.

Foi somente no início do século passado que, de modo generalizado, as assembléias populares assumiram a produção jurídica do direito civil.

A afirmação de que o estado liberal do laissez-faire, laissez-passer, foi um Estado de atividade restrita não é, portanto, inteiramente verdadeira, quando se dá conta de que foi então, que o Estado alargou seus poderes, fazendo sua, a faculdade de criar o direito da sociedade.

Nesta análise, a oposição conceitual entre sociedde e Estado não pode ser esquecida. A sociedade vive sob o signo da colaboração; seus membros são, como diz a palavra, sócios.

Já o Estado é uma criação artificial; vive sob o signo da hierarquia, tem tempo histórico definido.

Seguem-se daí diferenças profundas entre os dois ramos do direito, o estatal, ou público, e o social, ou privado. $\mathrm{O}$ direito público é um direito "bolado", se me for permitida a gíria; ele se faz per modum determinationis como seu conteúdo ético está antes nos fins que no conteúdo das normas; nele, tem vastas possibilidades a imaginação criadora. Já o direito privado brota naturalmente do povo; ele se faz lentamente e é obtido per modum conclusionis; seu caráter ético é, em princípio, intrínseco às suas normas. A atitude do jurista, diante dele, não pode ser a do criador revolucionário, e sim, a do observador beato que, com humildade, procura saber o que quer o povo. Ora, reconhecido que direito privado é o direito social por excelência, pelo menos duas conclusões se impốem: $1^{\mathrm{a}}$ ) as conhecidas restriçōes à vontade individual, como os limites à liberdade de contratar, as regras sobre lesão, excessiva necessidade, revisão judicial de contratos, proteção ao consumidor, não são, como muitas vezes se diz, "exceções" em seu verdadeiro leito, o social - vê-se que as "exceções" são exigências de sua própria natureza, já que se trata de direito baseado na colaboração; 2a) o civilista não deve se pôr a imaginar soluções ideais para regulamentar a vida do povo.

Nesse sentido, não me parece correto, exemplificando, que se imponha 
a todos os brasileiros, o casamento sob o modelo modernista da família sem chefe. Não entra na mente dos brasileiros pobres, - homens e mulheres - que, por exemplo, na decisão sobre mudança da família, da Bahia para São Paulo, a palavra final sobre a fixação do domicílio conjugal não caiba ao marido, e sim, a um juiz. Uma norma como esta é uma violência contra os simples.

As modificações no direito privado não podem ser dessa forma. As soluções novas devem ser admitidas, mas, à moda romana, isto é, sem eliminação das antigas, com justaposição para escolha pelas partes; por aluvião, não por avulsão.

Eis aí, senhoras e senhores, algumas idéias que me pareceram devessem ser expressas. O final retórico seria de se esperar, mas já escrevia Cícero "a cada um, o seu". Prefiro terminar, dizendo o que realmente sei: que Deus, é rico em misericórdia. Por isso, peço: Pai, que seu Espírito ilumine os que me ouvem e abençoe o povo brasileiro.

Arcadas, 26 de novembro de 1986. 